\title{
Product Development Protocol
}

National Cancer Institute

\section{Source}

National Cancer Institute. Product Development Protocol. NCI Thesaurus. Code C70875.

A regulatory plan or strategy submitted to the FDA proposing the approval of a new device for marketing in the U.S. It includes a demonstration of the safety and efficacy of the device. 